Journal of Engineering and Applied Sciences 14 (Special Issue 5): 8940-8943, 2019

ISSN: 1816-949X

(C) Medwell Journals, 2019

\title{
The Effect of Nanoscale Coating on Corrosion and Thermal Conductivity of the Tube in Solar Collectors
}

\author{
Ahmed Essa Faisal, Akeel Hssain Kadium and Qasim Saad Abdul Wahid \\ Department of Mechanical Engineering, College of Engineering, \\ University of Al-Qadisiyah, Iraq
}

\begin{abstract}
In the study the main causes of corrosion which affect the copper tubes of solar collectors that are used for heating and water supply systems are studied as well as the effect of using the nanocoatings of copper tubes with titanium oxide and graphene to reduce the probability of corrosion and the effect of the coating on the thermal conductivity and performance of collectors. The dependence of the attenuation and absorption coefficients of titanium and Graphene nanocoating on the titanium oxide and graphene concentrations is graphically illustrated and at the end a comparison of the efficiency of solar collectors depending on the coating material was made.
\end{abstract}

Keywords: Solar collector, corrosion, nanocoating

\section{INTRODUCTION}

The amount of solar energy received by the Earth in just one hour is more than what the population of the planet needs throughout the year, while more than a third of the energy consumed in the world is spent on heat supply of buildings (Bhattacharya et al., 2016).

The total flux of solar energy, intercepted by the Earth's, depending on the location on any particular day, is $100-250 \mathrm{~W} / \mathrm{m}^{2}$, with peak values at noon up to $1000 \mathrm{~W} / \mathrm{m}^{2}$. This is equivalent to burning $100-150 \mathrm{~kg}$ of fuel equivalent per $\mathrm{m}^{2}$ per year (Arndt and Nicolaus, 2014). The undoubted advantages of using solar energy are the absence of environmental pollution by collateral products and waste from fuel combustion in boilers, as well as the absence of heat emissions to the atmosphere during combustion of fuel, which increases the thermal pollution, one of the causes of global warming (Ivanovna et al., 2016). That is why the use of solar energy as a heat source for heating residential and industrial premises and heating water for domestic use is of paramount importance worldwide.

Solar collector and problems of its using: The solar collector (Fig. 1) is the main element which directly involved in heating the coolant for heating buildings or heating water in water supply systems.

Operating experience of solar collectors has shown that one of the most frequent causes of failure of a collector during long-term use is coolant leakage from copper pipes as a result of penetrating corrosion, while the main causes of corrosion of copper collector pipes are Kyriaki et al. (2015):

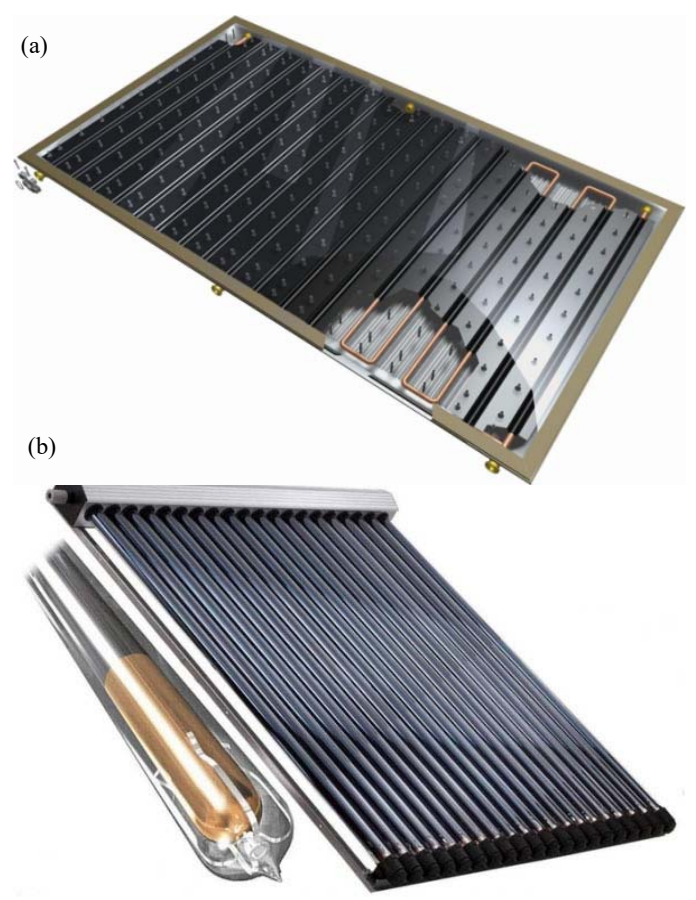

Fig. 1(a-b): Tubular solar collector

- Chlorides presence in water used for disinfection in urban water supply and impurities

- The occurrence of electrolysis in aqueous solution as a result of hitting the surface of copper pipes by the metal particles from water pipes (Fig. 2)

- Copper erosion (Fig. 3) in devices that change the direction of water movement (fittings, bends, tees) as a result of movement of water under pressure

Corresponding Author: Ahmed Essa Faisal, Department of Mechanical Engineering, College of Engineering, University of Al-Qadisiyah, Iraq 


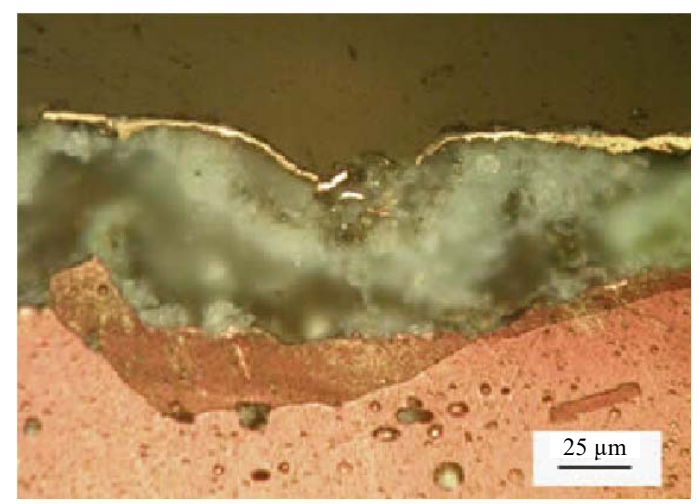

Fig. 2: The electrolysis of copper in an aqueous solution

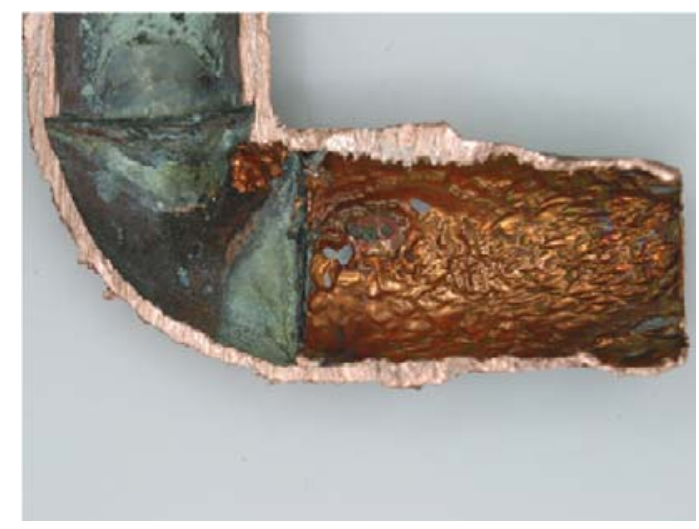

Fig. 3: Copper erosion

In heating systems, the problem of corrosion due to the presence of chlorides in water and the occurrence of electrolysis is easily solved by using specialized glycol solutions as a coolant containing corrosion inhibitors which block the reproduction of algae and bacteria biocides in the system. Such inhibitors are not allowed to use in water supply systems (Speight, 2015).

The main directions of reducing the probability of copper tubes corrosion of solar collectors in water supply systems are Speight (2015) and Burleigh et al. (2014):

- Improving water quality by installing filters that reduce the water aggressiveness

- Using systems with a hot water tank isolated from the collector

- Covering the inner surface of copper tubes by coatings that increase its service life

Since the use of filters does not allow to completely clean up water from impurities and chlorides, in addition collectors with built-in storage tanks are currently practically not used. The main focus of research and development at present is to reduce the copper tubes corrosion of solar collectors by applying coatings on the inner side, allowing reducing the probability of corrosion.

Use of coatings for corrosion protection: One of the easiest ways to protect copper from corrosion is the chrome plating of copper. Chrome plating has good protection against high-temperature oxidation of copper, however, the effectiveness of its protection against corrosion in aqueous solutions has not been proven and as a result did not find a wide application (Menk et al., 2019).

Good results have been shown by studies of the use of polymer coatings to protect copper from corrosion. In particular, to protect against corrosion in water and acid solutions, polyaniline is used, the effectiveness of which has been proven at various temperatures, humidity and voltage (Brusic et al., 1997).

Nowadays the development of such a field of science as nanotechnology allows synthesizing new materials and coatings, which are also used to protect metals from external influences and corrosion (Tator, 2014). To protect the copper tubes of the solar collector, the coating of copper tubes with titanium films $\mathrm{TiO}_{2}$ as well as graphene-based films has now found use.

Titanium films have good corrosion resistance, high absorption capacity and high transmittance of infrared emission. In this case, titanium films are applied both to the inner surface and to the outer surface by the method of vapor deposition. Titanium film nanocoatings provide a high solar absorption coefficient $\langle=0.95$ and a low emissivity $\Sigma=0.05$, almost completely replacing black chrome and black nickel coatings (Noel et al., 2018).

Graphene as a material was first experimentally studied in 2004 by Andre Geim and Konstantin Novoselov. For applying the graphene on copper tubes, a chemical vapor deposition technique is used, commonly used for the production of diamond sprays, silicon films and carbon nanotubes.

Further, the effect of anticorrosive titanium and graphene nanocoatings on the thermal conductivity of solar collector tubes is considered in more detail.

Effect of nanocoatings on the thermal conductivity of tubes and the efficiency of solar collectors: Despite the fact that the thermal conductivity of titanium spraying at room temperature is $18.85 \mathrm{~W} /(\mathrm{m} . \mathrm{K})$ and the thermal conductivity of graphene measured at room temperature ranges from $4.84 \times 10^{3}$ to $5.3 \times 10^{3} \mathrm{~W} /(\mathrm{m} . \mathrm{K}$ ) (Akbar et al., 2015). The difference in the performance of collectors with titanium and graphene coating is not so great, contrary to expectations. So, for the considered coatings, the size of nanoparticles is no more than $100 \mathrm{~nm}$, while the coefficient of spectral absorption of the coating is determined by the following expression: 


$$
\sigma_{\mathrm{f}}=\frac{4 \pi \times \mathrm{k}_{\mathrm{f}}}{\lambda}
$$

Where:

$\mathrm{k}_{\mathrm{f}}=$ Coating attenuation index

$L=$ Wavelength

Due to the small value of the solar absorption coefficient $(k 1)$, the equations for calculating the coefficients of scattering, absorption and total effective absorption are as follows:

$$
\begin{gathered}
\mathrm{Q}_{\text {pacc }}=\frac{8}{3} \mathrm{a}^{4} \operatorname{Re}\left[\left(\frac{\mathrm{m}^{2}-1}{\mathrm{~m}^{2}+2}\right)\right] \\
\mathrm{Q}_{\mathrm{a} \text { cop } 6}=4 \mathrm{alm}\left[\frac{\mathrm{m}^{2}-1}{\mathrm{~m}^{2}+2}\left(1+\frac{\mathrm{a}^{2}}{15}\left(\frac{\mathrm{m}^{2}-1}{\mathrm{~m}^{2}+2}\right) \frac{\mathrm{m}^{4}+27 \mathrm{~m}^{2}+38}{2 \mathrm{~m}^{2}+3}\right)\right] \\
\mathrm{z}_{\text {total }}=\mathrm{Q}_{\text {absorb }}+\mathrm{Q}_{\text {scatt }}
\end{gathered}
$$

Where:

$\mathrm{m}$ = Relative complex refractive index of nanocoating;

$\langle=$ Dimensional parameter depends on the particle size of the nanomaterial $D$ and the wavelength $L$

For a known coefficient of total effective absorption, we can write the expression of the spectral absorption of nanoparticles in the following form:

$$
\sigma_{\mathrm{p}}=\frac{3 \pi \times \mathrm{f}_{\mathrm{v}} \times \mathrm{Q}_{\text {total }}}{2 \mathrm{D}}
$$

where, $f_{v}$ is concentration of nanomaterial in the primary vapor mixture

Considering that the nanomaterial particles have a uniform structure, the scattering coefficient is usually very small and is neglected. Then the total absorption coefficient is calculated by the following expression:

$$
\sigma=\sigma_{\mathrm{f}}+\sigma_{\mathrm{p}}=\frac{4 \pi \times \mathrm{k}_{\mathrm{f}}}{\lambda}+\frac{3 \pi \times \mathrm{f}_{\mathrm{v}} \times \mathrm{Q}_{\text {total }}}{2 \mathrm{D}}
$$

Figure 4 and 5 show the dependence of the emitting attenuation coefficient on the wavelength for various values of the concentration of titanium oxide and Graphene in the primary vapor mixture.

Figure 6 and 7 show the dependences of the absorption coefficient of titanium and Graphene nanocoatings on the wavelength for various values of the concentration of the primary vapor mixture.

To assess the performance of solar collectors with different anti-corrosion coatings, a study, shown in Fig. 8, of the instantaneous efficiency of collectors depending on the coefficient of temperature difference was done.

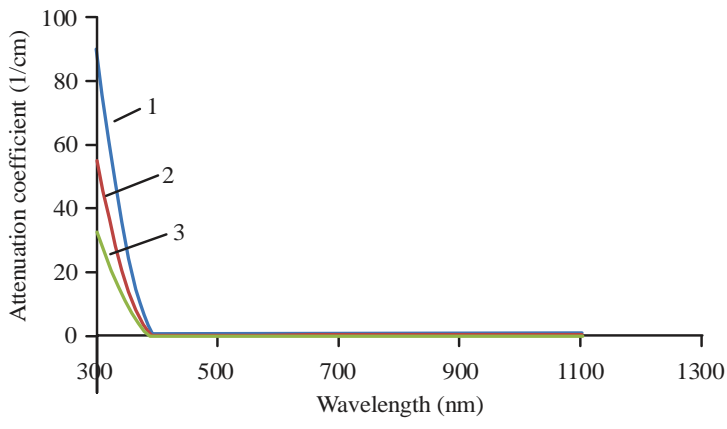

Fig. 4: The emitting attenuation coefficient of titanium nanocoating

(1) Concentration of titanium oxide in the primary vapor of $3 \%$, (2) Concentration of titanium oxide in the primary vapor of $5 \%$ and (3) Concentration of titanium oxide in the primary vapor of $8 \%$

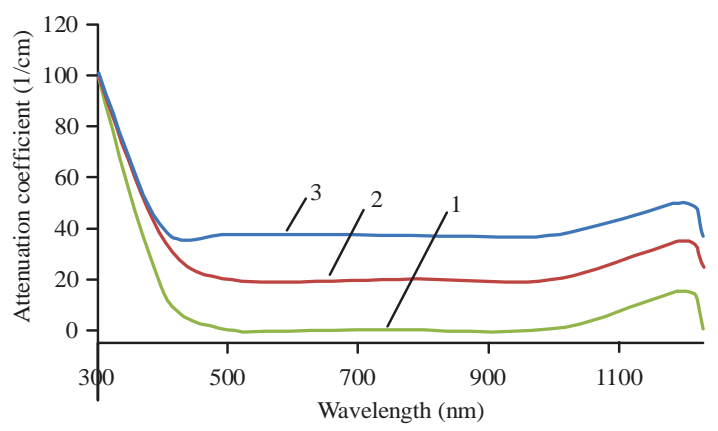

Fig. 5: Graphene emitting attenuation coefficient 1: Graphene concentration 2\%, 2: Graphene concentration $5 \%$ and 3: Graphene concentration of $10 \%$

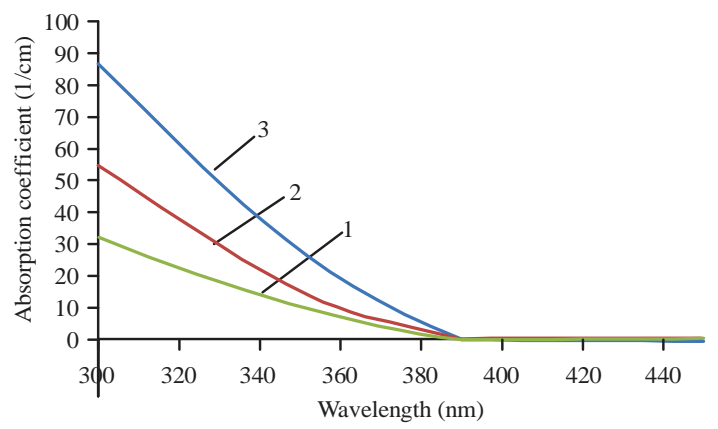

Fig. 6: The dependence of the absorption coefficient of titanium nanocoating

1: Concentration of titanium oxide in the primary vapor of $3 \%$, 2: Concentration of titanium oxide in the primary vapor of $5 \%$ and 3 : Concentration of titanium oxide in the primary vapor of $8 \%$

The coefficient of temperature difference is calculated by the following expression:

$$
\mathrm{X}=\frac{\mathrm{T}^{\mathrm{m}}-\mathrm{T}^{\mathrm{a}}}{\mathrm{G}}
$$




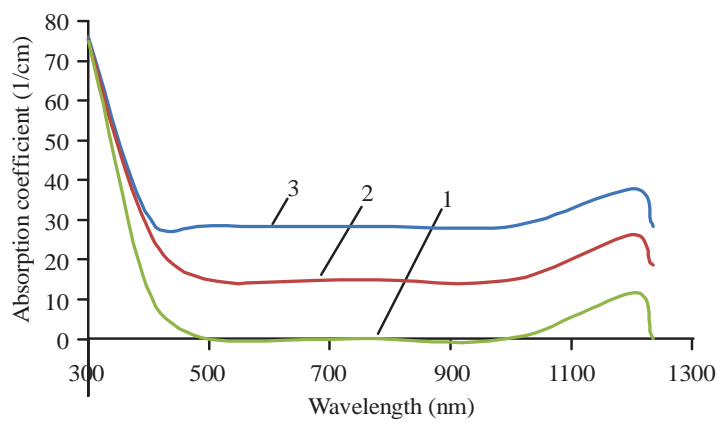

Fig. 7: The dependence of the absorption coefficient of Graphene nanocoatings

1: Graphene concentration 2\%, 2: Graphene concentration $5 \%$ and 3: Graphene concentration of $10 \%$

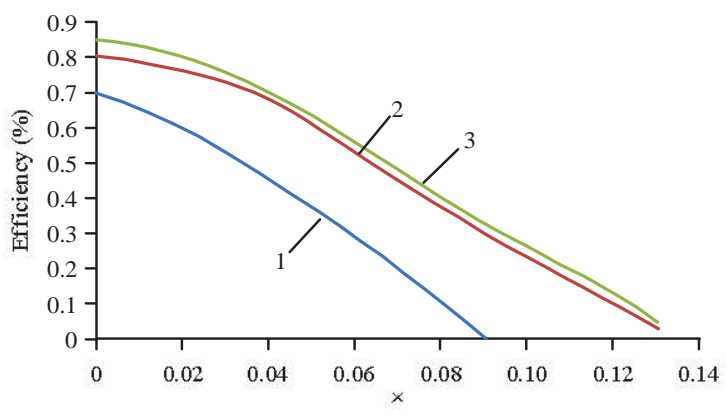

Fig. 8: Comparison of the efficiency of solar collectors 1: Standard collector, 2: Collector with titanium nanocoating tubes and 3 : Collector with graphene nanocoating

Where:

$\mathrm{T}^{\mathrm{m}}=$ Water temperature

$\mathrm{T}^{\mathrm{a}}=$ Ambient temperature

$\mathrm{G}=$ Instant solar emission

\section{CONCLUSIONS AND RECOMMENDATIONS}

As a result of the research, it was found that, despite the fact that the thermal conductivity of graphene ranges from $4.84 \times 10^{3}$ to $5.3 \times 10^{3} \mathrm{~W} /(\mathrm{m} . \mathrm{K})$ compared to the thermal conductivity of titanium deposition $18.85 \mathrm{~W} /(\mathrm{m} . \mathrm{K})$, the efficiency of the solar collector with titanium and graphene has no significant differences. This is due to the fact that the coefficients of attenuation and absorption of titanium at wavelengths greater than $400 \mathrm{~nm}$ is almost zero, while for the Graphene coating, these figures are achieved only at low concentrations of the substance in the deposited mixture.

The results show that by knowing the thermal conductivity of the nanocoatings, it is impossible to draw unambiguous conclusions about its influence on the efficiency of the collector, therefore, it is necessary to perform studies for each specific coating or material.

\section{REFERENCES}

Akbar, F., M. Kolahdouz, S. Larimian, B. Radfar and H.H. Radamson, 2015. Graphene synthesis, characterization and its applications in nanophotonics, nanoelectronics and nanosensing. J. Mater. Sci.: Mater. Electron., 26: 4347-4379.

Arndt, S. and M. Nicolaus, 2014. Seasonal cycle and long-term trend of solar energy fluxes through Arctic Sea ice. Cryosphere, 8: 2219-2233.

Bhattacharya, M., S.R. Paramati, I. Ozturk and S. Bhattacharya, 2016. The effect of renewable energy consumption on economic growth: Evidence from top 38 countries. Applied Energy, 162: 733-741.

Brusic, V., M. Angelopoulos and T. Graham, 1997. Use of polyaniline and its derivatives in corrosion protection of copper and silver. J. Electrochem. Soc., 144: 436-442.

Burleigh, T.D., C.G. Gierke, N. Fredj and P.J. Boston, 2014. Copper tube pitting in Santa Fe municipal water caused by microbial induced corrosion. Materials, 7: 4321-4334.

Ivanovna, K.T., S.S. Alekseevich, R.Y. Vladimirovich and I.N. Yuryevich, 2016. Efficiency of use of solar collectors for heating buildings in Penza region. Reg. Archit. Constr., 4: 93-99, (In Russian).

Kyriaki, E., V. Drosou and A.M. Papadopoulos, 2015. Solar thermal systems for low energy hotel buildings: State of the art, perspectives and challenges. Energy Procedia, 78: 1968-1973.

Menk, L.A., E. Baca, M.G. Blain, J. McClain, J. Dominguez, A. Smith and A.E. Hollowell, 2019. Galvanostatic plating with a single additive electrolyte for bottom-up filling of copper in Mesoscale TSVs. J. Electrochem. Soc., 166: D3226-D3231.

Noel, J.J., N. Ebrahimi and D.W. Shoesmith, 2018. Corrosion of Titanium and Titanium Alloys. In: Encyclopedia of Interfacial Chemistry: Surface Science and Electrochemistry, Wandelt, K. (Ed.). Elsevier Science, Amsterdam, Netherlands, ISBN: 9780128098943 , pp: 192-200.

Speight, J.G., 2015. Corrosion. In: Handbook of Offshore Oil and Gas Operations, Speight, J.G. (Ed.)., Subsea and Deepwater Oil and Gas Science and Technology, Chapter 8. Gulf Professional Publishing, USA., ISBN: 978-1-85617-558-6, pp: 213-256.

Tator, K.B., 2014. Nanotechnology: The future of coatings-part 1. Mater. Perform., 53: 34-36. 